This is the final peer-reviewed accepted manuscript of:

Roberto Di Giulio, Andrea Boeri, Danila Longo, Valentina Gianfrate, Saveria O.M. Boulanger \& Chiara Mariotti (2019): ICTs for Accessing, Understanding and Safeguarding Cultural Heritage: The Experience of INCEPTION and ROCK H2020 Projects, International Journal of Architectural Heritage, elSSN:1558-3058

The final published version is available online at:

https://doi.org/10.1080/15583058.2019.1690075

Rights / License:

The terms and conditions for the reuse of this version of the manuscript are specified in the publishing policy. For all terms of use and more information see the publisher's website. 

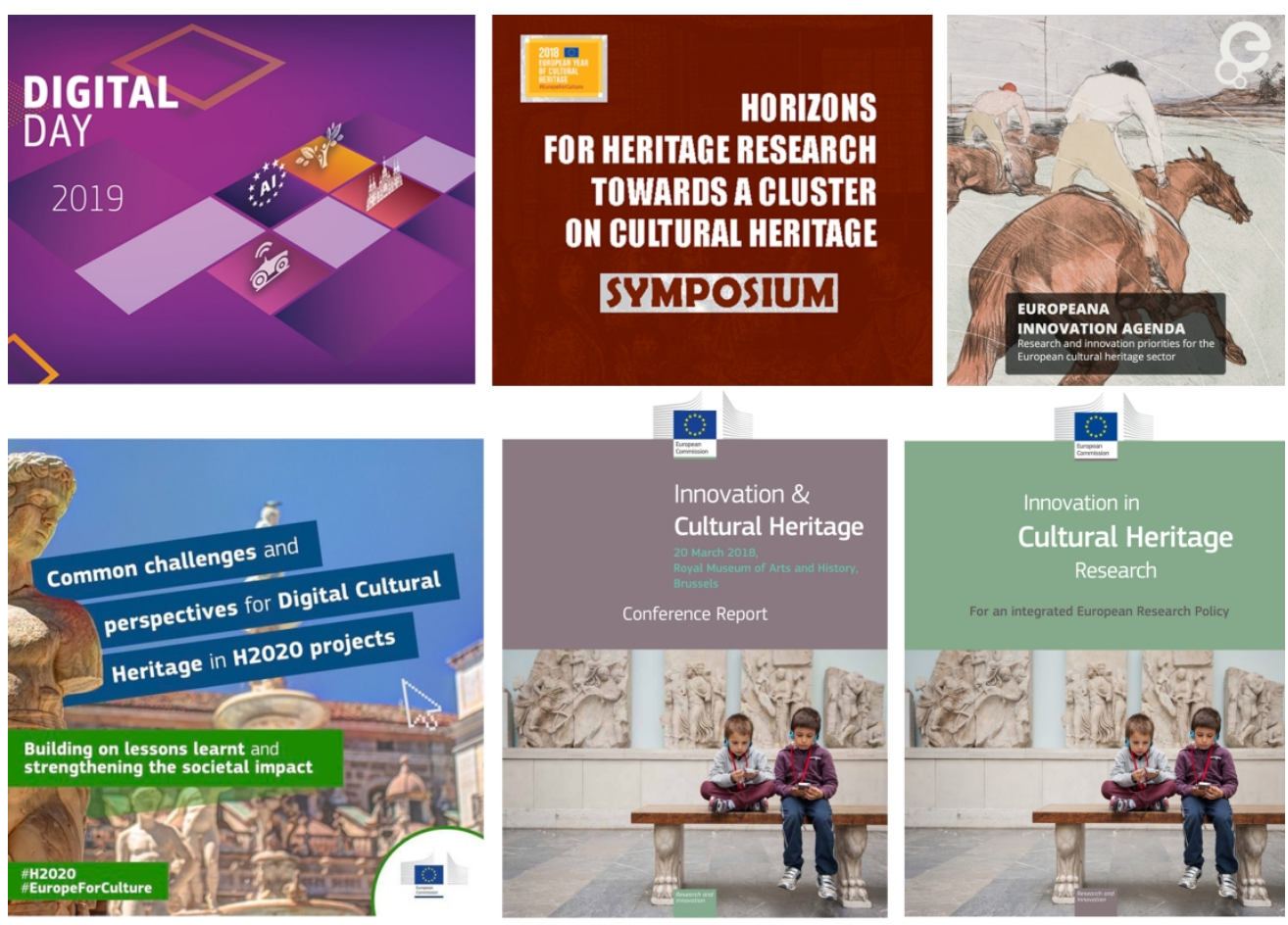

\section{8 \\ ANNO EUROPEO \\ DEL PATRIMONIO \\ CULTURALE \\ \#EuropeForCulture}
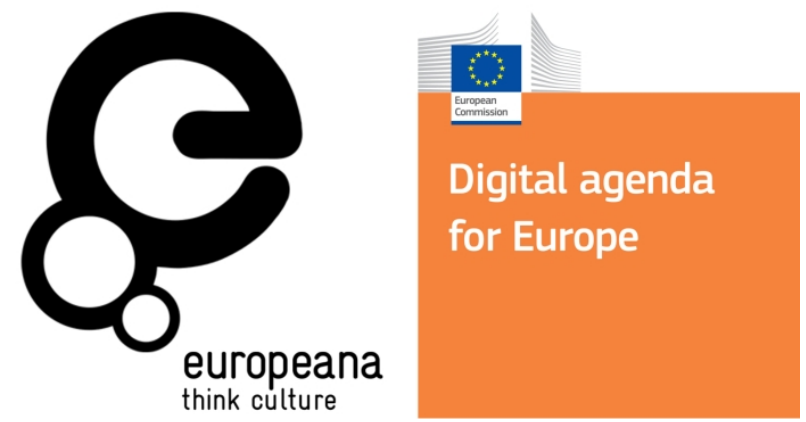

Fig. 1: Recent main events in the field of $\mathrm{CH}$ digitisation across Europe. (Design by Chiara Mariotti). $180 \times 189 \mathrm{~mm}(300 \times 300 \mathrm{DPI})$ 


\section{"Making our cultural heritage widely available in the digital era is vital"}

Fig. 2: Timeline of $\mathrm{CH}$ digitisation across Europe (Design by Chiara Mariotti).

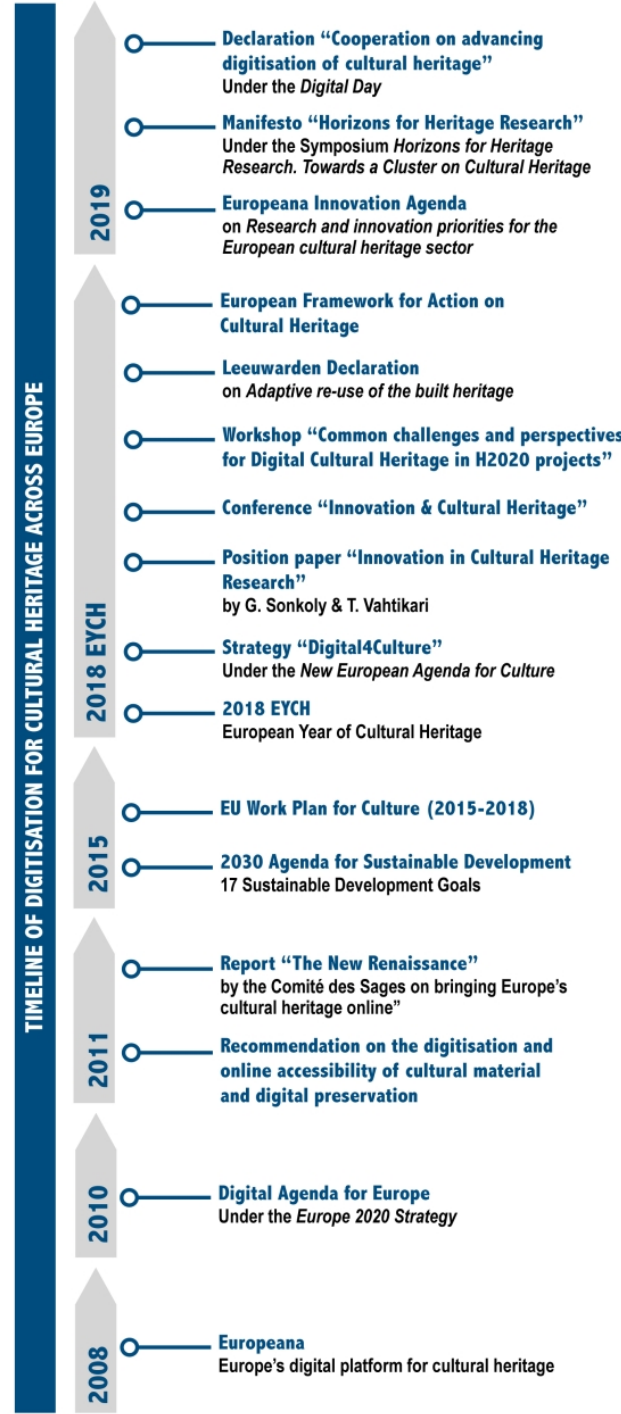

Digital Day 2019

กั

$209 \times 287 \mathrm{~mm}(300 \times 300 \mathrm{DPI})$ 


\begin{tabular}{|c|c|c|c|}
\hline N & Acronym & Coord. & CH Digital Approach used \\
\hline 1 & $\begin{array}{l}\text { INCEPTION } \\
\text { (H2020) RIA }\end{array}$ & IT & 3D digital reconstruction for HBIM, semantic web platform. \\
\hline 2 & $\begin{array}{l}\text { iMareCulture } \\
\text { (H2020) RIA }\end{array}$ & CYP & $\begin{array}{l}\text { Use of open GIS data, creation of 3D libraries, 3D automatic recognition and } \\
\text { localization of objects. }\end{array}$ \\
\hline 3 & $\begin{array}{l}\text { GRAVITATE } \\
\text { (H2020) RIA }\end{array}$ & UK & $\begin{array}{l}\text { 3D geometry, shape analysis, color features, semantic metadata and natural } \\
\text { language processing, decision support platform. }\end{array}$ \\
\hline 4 & $\begin{array}{l}\text { Time Machine } \\
\text { (H2020) CSA }\end{array}$ & $\mathrm{CH}$ & $\begin{array}{l}\text { Use of Big Data of the Past, systematization of archive with the creation of a } \\
\text { digital information system. }\end{array}$ \\
\hline 5 & $\begin{array}{c}\text { ViMM } \\
\text { (H2020) CSA }\end{array}$ & CYP & Virtual Reality applied to Museums. \\
\hline 6 & $\begin{array}{l}\text { EMOTIVE } \\
\text { (H2020) RIA }\end{array}$ & UK & $\begin{array}{l}\text { Virtual Museums, "emotive storytelling", creation of high-quality, interactive, } \\
\text { personalized digital stories. }\end{array}$ \\
\hline 7 & $\begin{array}{l}\text { NewsEye } \\
\text { (H2020) RIA }\end{array}$ & $F R$ & $\begin{array}{l}\text { Digital investigation on Historical Newspaper, with text recognition, text analysis, } \\
\text { natural language processing, computational creativity and natural language } \\
\text { generation. }\end{array}$ \\
\hline 8 & $\begin{array}{l}\text { Pluggy } \\
\text { (H2020) RIA }\end{array}$ & EL & $\begin{array}{l}\text { Web architecture for pluggable applications, allowing not yet imagined ways to } \\
\text { utilize the content on the social platform. Apps include Augmented Reality, } \\
\text { Geolocalisation, 3D Sonic Narratives (audio), gaming Apps. }\end{array}$ \\
\hline 9 & $\begin{array}{l}\text { SILKNOW } \\
\text { (H2020) RIA }\end{array}$ & ES & $\begin{array}{l}\text { Semantically relating digitized European silk heritage, enabling data } \\
\text { interoperability across different collections, for advanced searching abilities. } \\
\text { Building a "Virtual Loom" to clone weaving techniques. Visual tools that show } \\
\text { the spatio-temporal relationships of data, including an open-access, multilingual } \\
\text { thesaurus. }\end{array}$ \\
\hline 10 & $\begin{array}{c}\text { TROMPA } \\
\text { (H2020) RIA }\end{array}$ & ES & $\begin{array}{l}\text { Digitization of repertoire, crowd annotation, analysis through automated } \\
\text { processing. }\end{array}$ \\
\hline 11 & $\begin{array}{l}\text { COHERE } \\
\text { (H2020) RIA }\end{array}$ & UK & $\begin{array}{l}\text { Digital heritage dialogue[s]: the role of digitally-enabled conversations in } \\
\text { constructing heritage identities in Europe engages with digital design } \\
\text { methodologies to investigate heritage conversations online and on-site. web- } \\
\text { and mobile-based, alongside experimental bespoke tools for use in museums } \\
\text { and sites. }\end{array}$ \\
\hline 12 & $\begin{array}{l}\text { COHESIFY } \\
\text { (H2020) RIA }\end{array}$ & UK & $\begin{array}{l}\text { Mixed-methods design including an original and representative survey of } \\
\text { citizens in a sample of EU regions, quantitative and qualitative analysis of EU- } \\
\text { wide data and of programme implementation and communication strategies in a } \\
\text { sample of regions, framing and sentiment analysis of online and offline media } \\
\text { and focus groups with citizens. }\end{array}$ \\
\hline 13 & $\begin{array}{c}\text { COURAGE } \\
\text { (H2020) RIA }\end{array}$ & $\mathrm{HU}$ & $\begin{array}{l}\text { Online database of collections in open source, online education materials, } \\
\text { educational games. }\end{array}$ \\
\hline 14 & $\begin{array}{l}\text { CRIC } \\
\text { (H2020) MSCA- } \\
\text { RISE }\end{array}$ & UK & The project mainly uses storytelling both with ans without digital supports. \\
\hline 15 & $\begin{array}{l}\text { CULTURALBASE } \\
\text { (H2020) CSA }\end{array}$ & ES & $\begin{array}{l}\text { Social Platform that involves a combination of traditional and innovative modes } \\
\text { of communication. This social platform has been conceived as a double-shaped } \\
\text { process enabling interactions and work dynamics stemming from the shared } \\
\text { identification and formulation of the most urgent topics and issues to be } \\
\text { addressed in further research initiatives resulting from a specific research } \\
\text { agenda. }\end{array}$ \\
\hline 16 & $\begin{array}{l}\text { EUNAMUS } \\
\text { (FP7) CP-FP }\end{array}$ & SE & Platform to systematize information on national museums. \\
\hline 17 & $\begin{array}{l}\text { PERCEIVE } \\
\text { (H2020) RIA }\end{array}$ & IT & $\begin{array}{l}\text { PERCEIVE will produce a computer simulation environment and embed it into a } \\
\text { virtual platform that cohesion policy stakeholders will be able to use and } \\
\text { produce what-if analysis and long-term scenario analysis of the effects of } \\
\text { policies. Creation of a Virtual Learning Environment. }\end{array}$ \\
\hline 18 & $\begin{array}{l}\text { RICHES } \\
\text { (FP7) CP-FP }\end{array}$ & UK & Interactive showcase, taxonomy on $\mathrm{CH}$, virtual performances. \\
\hline 19 & $\begin{array}{l}\text { SIGNHUB } \\
\text { (H2020) RIA }\end{array}$ & ES & $\begin{array}{l}\text { Digital grammars of } 6 \text { sign languages, produced with a new online grammar } \\
\text { writing tool; an interactive digital atlas of linguistic structures of the world's sign } \\
\text { languages; online sign language assessment instruments for education and } \\
\text { clinical intervention, and the first digital archive of life narratives by elderly } \\
\text { signers, subtitled and partially annotated for linguistic properties. }\end{array}$ \\
\hline
\end{tabular}

Fig. 3: Analyses of digital approaches of 19 selected projects (Design by Saveria O.M. Boulanger). $209 \times 297 \mathrm{~mm}(300 \times 300 \mathrm{DPI})$ 
Fig. 4: Short description of the selected projects (Design by Saveria O.M. Boulanger).

$209 \times 297 \mathrm{~mm}(300 \times 300 \mathrm{DPI})$ 


\begin{tabular}{|c|c|c|}
\hline 13 & $\begin{array}{l}\text { COURAGE } \\
\text { (H2020) RIA }\end{array}$ & $\begin{array}{l}\text { The project proposes both to create an electronic registry of representative online and } \\
\text { offline, private and public collections of cultural opposition in all former socialist countries in } \\
\text { Europe and to study the origins, uses and changing roles of these collections in their social, } \\
\text { political and cultural contexts. }\end{array}$ \\
\hline 14 & $\begin{array}{c}\text { CRIC } \\
\text { (H2020) MSCA- } \\
\text { RISE }\end{array}$ & $\begin{array}{l}\text { The objective of the "Cultural Narratives of Crisis and Renewal" project is to examine } \\
\text { cultural production and cultural practices in periods of societal crisis at the turn-of the } 20 \text { th } \\
\text { Century on both sides of the Atlantic. The overarching aim of the project is to investigate the } \\
\text { role of cultural production, not just as a vehicle to elaborate cohesive narratives in moments } \\
\text { of crisis, but as a space to create alternative imaginaries for social renewal. }\end{array}$ \\
\hline 15 & $\begin{array}{l}\text { CULTURALBASE } \\
\text { (H2020) CSA }\end{array}$ & $\begin{array}{l}\text { The Cultural Base Plattorm has addressed the intensified relationship between cultural } \\
\text { identity, cultural heritage and cultural expression as part of the recent transformations of } \\
\text { culture in the context of digitization and globalization. It highlights the value of a } \\
\text { transnational approach to European heritage rather than viewing it as a collection of } \\
\text { national heritages. On the other hand, the project notes the challenge posed by } \\
\text { marginalised and excluded memories to both universalistic and national memories. }\end{array}$ \\
\hline 16 & $\begin{array}{l}\text { EUNAMUS } \\
\text { (FP7) CP-FP }\end{array}$ & $\begin{array}{l}\text { The project explored European national museums as spaces for the display and negotiation } \\
\text { of identities, values, citizenship and conflicts. It analysed the historical formation of national } \\
\text { museums together with contemporary museum policies and politics external to the } \\
\text { museums, which also play a major role in setting museum agendas. }\end{array}$ \\
\hline 17 & $\begin{array}{l}\text { PERCEIVE } \\
\text { (H2020) RIA }\end{array}$ & $\begin{array}{l}\text { The multidisciplinary project, drawing from nine regional case studies from seven countries, } \\
\text { investigates the understandings of EU citizens about the EU as institution, in particular how } \\
\text { the knowledge of citizens in different European regions construct their knowledge about the } \\
\text { EU. }\end{array}$ \\
\hline 18 & $\begin{array}{c}\text { RICHES } \\
\text { (FP7) CP-FP }\end{array}$ & $\begin{array}{l}\text { The project researches the context of change in which European Cultural Heritage is } \\
\text { transmitted, its implications for future Cultural Heritage practices and the frameworks } \\
\text { (cultural, legal, financial, educational, technical) to be put in place for the benefit of all } \\
\text { audiences and communities in the digital age. }\end{array}$ \\
\hline 19 & $\begin{array}{c}\text { SIGNHUB } \\
\text { (H2020) RIA }\end{array}$ & $\begin{array}{l}\text { The project has two main focuses. The first focus will be on sign language: the project will } \\
\text { create online grammars of } 6 \text { sign languages (and a sign language structure Atlas, and } \\
\text { develop tools for sign language assessment. The second, is the creation and making } \\
\text { available online of a digital archive of memories of elderly signers, which will serve as } \\
\text { documentation of the history, and linguistic and cultural heritage of Deaf communities in } \\
\text { several European countries since the mid-20th century. }\end{array}$ \\
\hline
\end{tabular}

Fig. 4: Short description of the selected projects (Design by Saveria O.M. Boulanger).

$209 \times 297 \mathrm{~mm}(300 \times 300 \mathrm{DPI})$ 


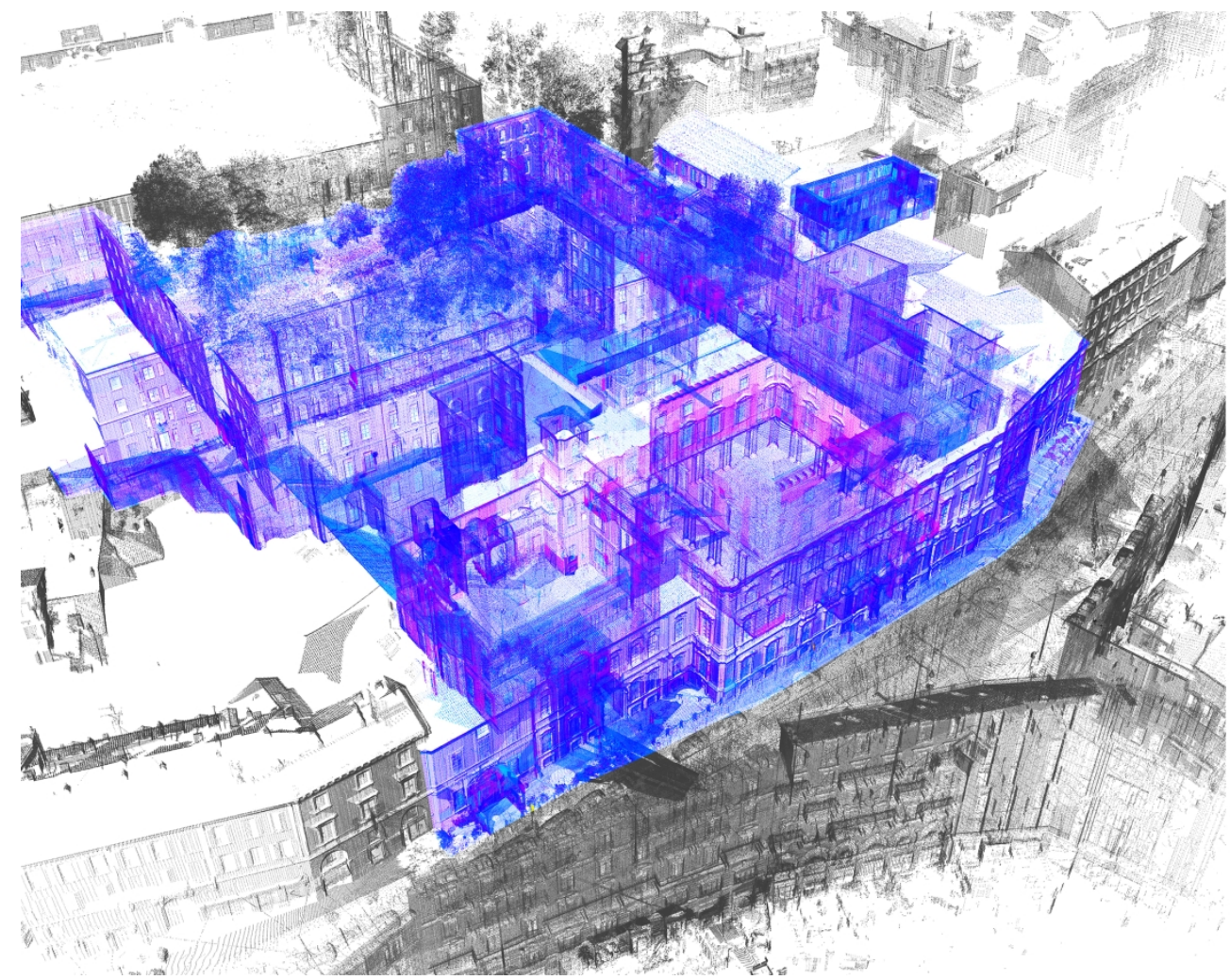

Fig. 5: INCEPTION, 3D survey of Palazzo Arese Litta, Milan, as an example of complex architectural space detected (survey and modelling by DIAPReM Center, Department of Architecture, University of Ferrara).

$209 \times 164 \mathrm{~mm}(300 \times 300 \mathrm{DPI})$ 

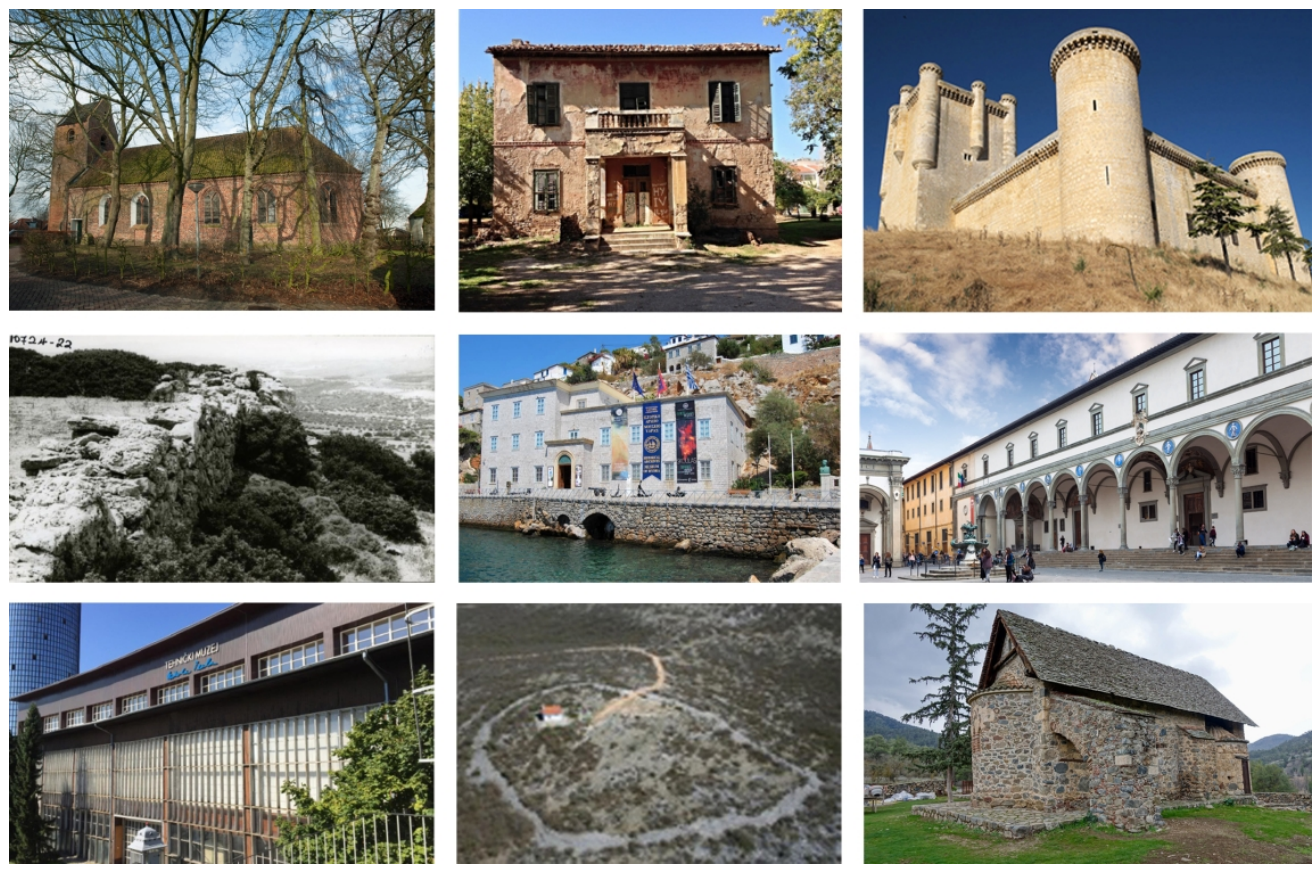

Fig. 6: INCEPTION 9 Demonstration Cases (Design by Chiara Mariotti).

$207 \times 136 \mathrm{~mm}(300 \times 300$ DPI $)$ 

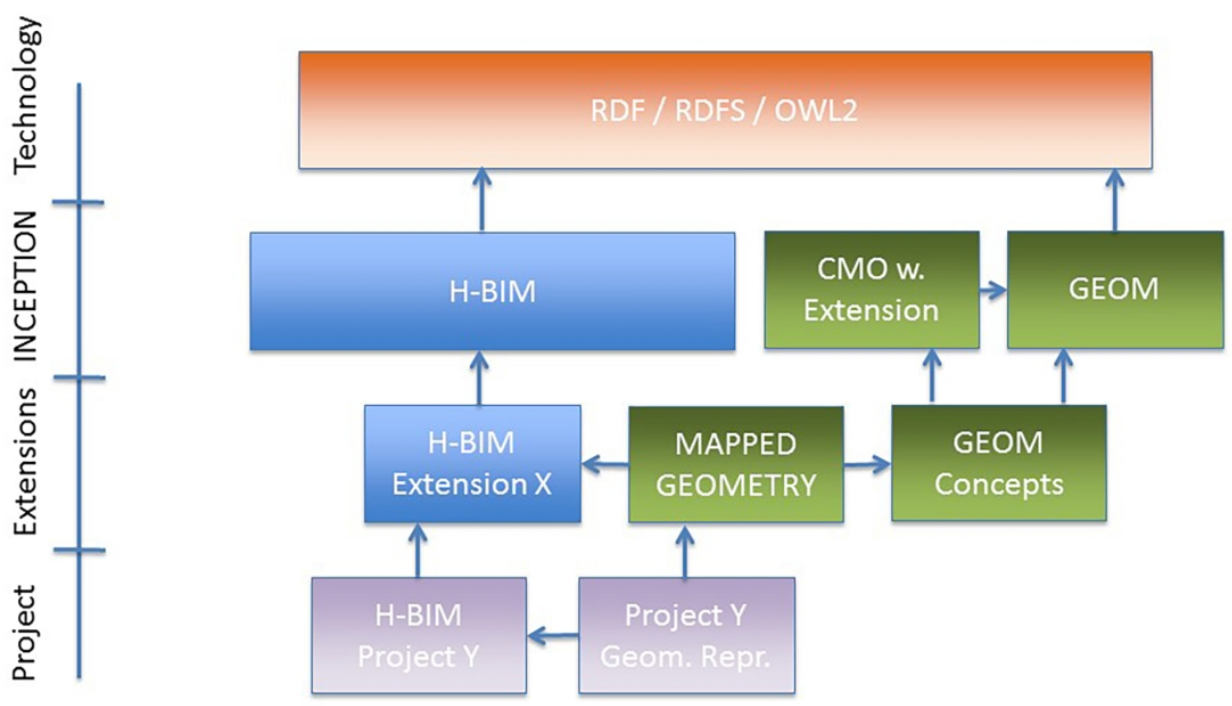

Fig. 7: INCEPTION H-BIM ontology layers structure (Design by Peter Bonsma).

$170 \times 100 \mathrm{~mm}(300 \times 300 \mathrm{DPI})$ 


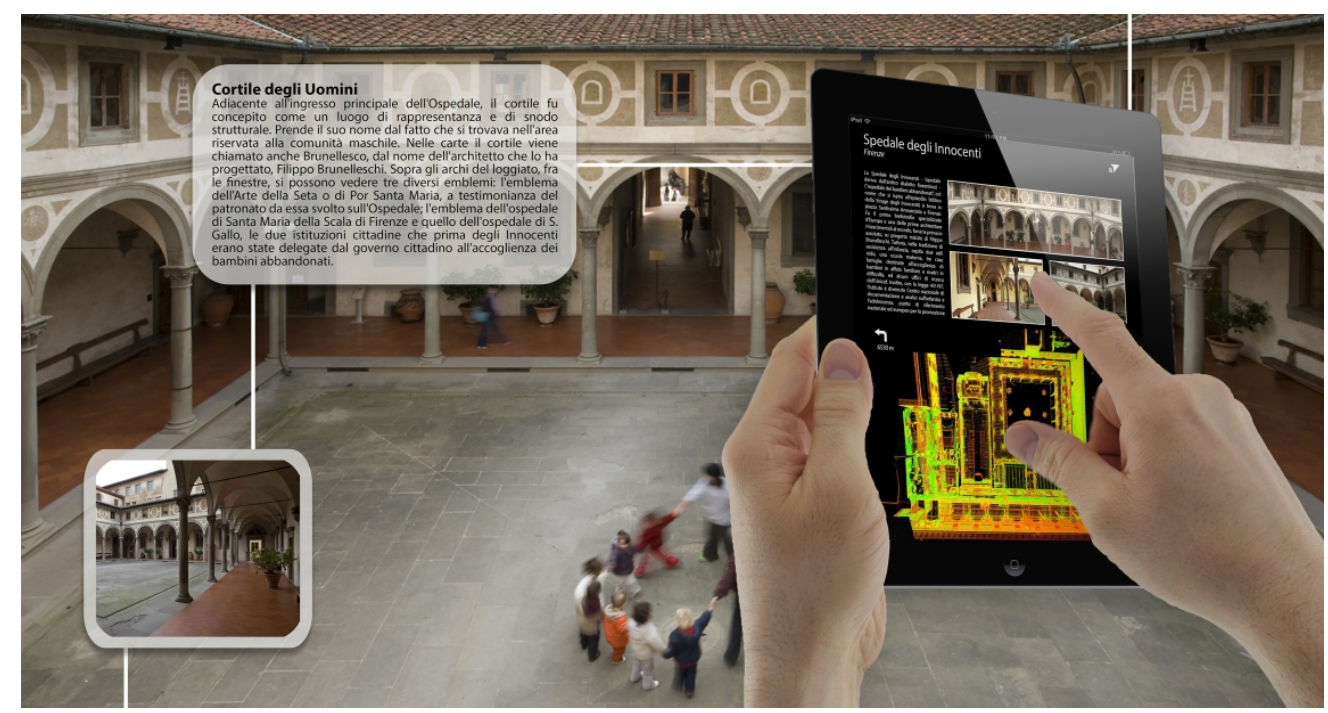

Fig. 8: INCEPTION, example of on-site application tested on the Italian Demonstration Case, the Istituto degli Innocenti (Design by Federico Ferrari).

$299 \times 159 \mathrm{~mm}(300 \times 300 \mathrm{DPI})$ 

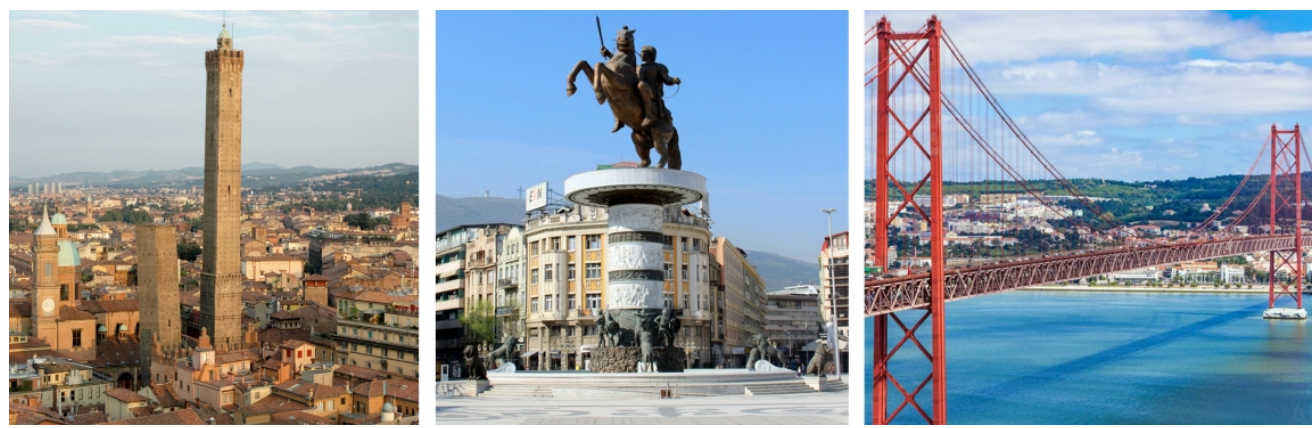

Fig. 9: ROCK 3 Demonstrative areas (Design by Chiara Mariotti).

$209 \times 66 \mathrm{~mm}(300 \times 300$ DPI $)$ 


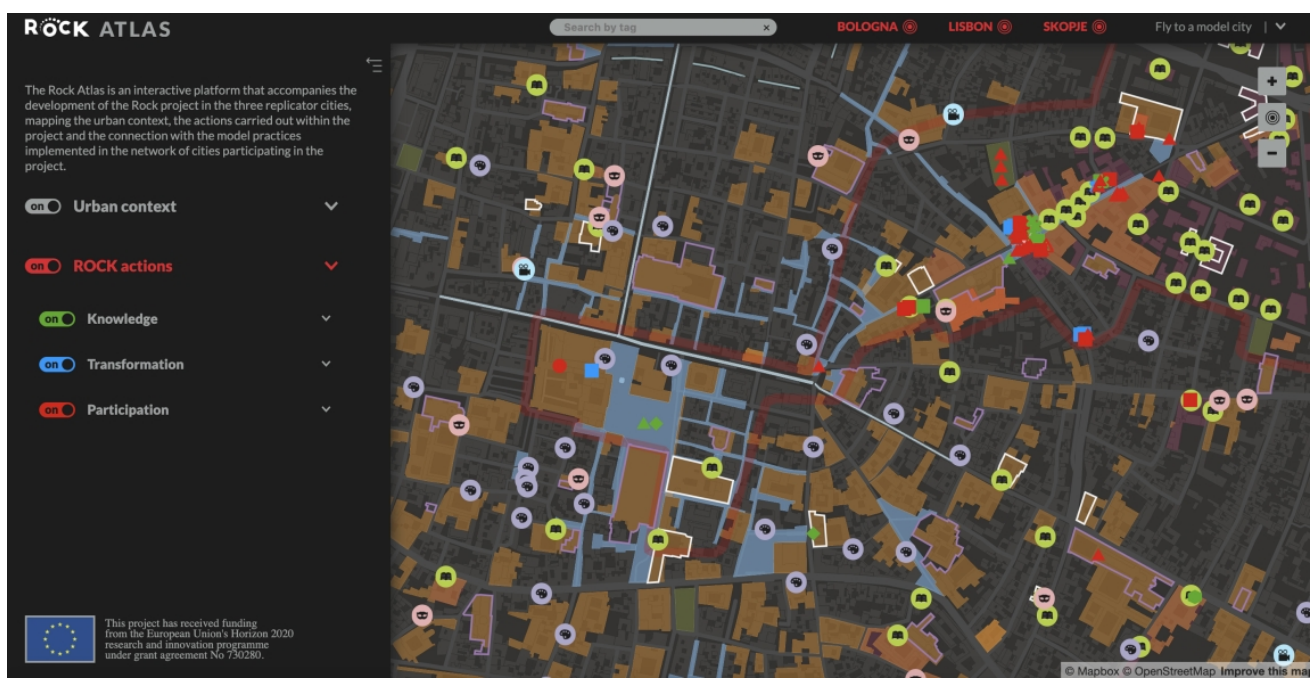

Fig. 10: Example of ROCK Atlas visualisation (https://atlas.rockproject.eu). $250 \times 127 \mathrm{~mm}(300 \times 300$ DPI $)$ 


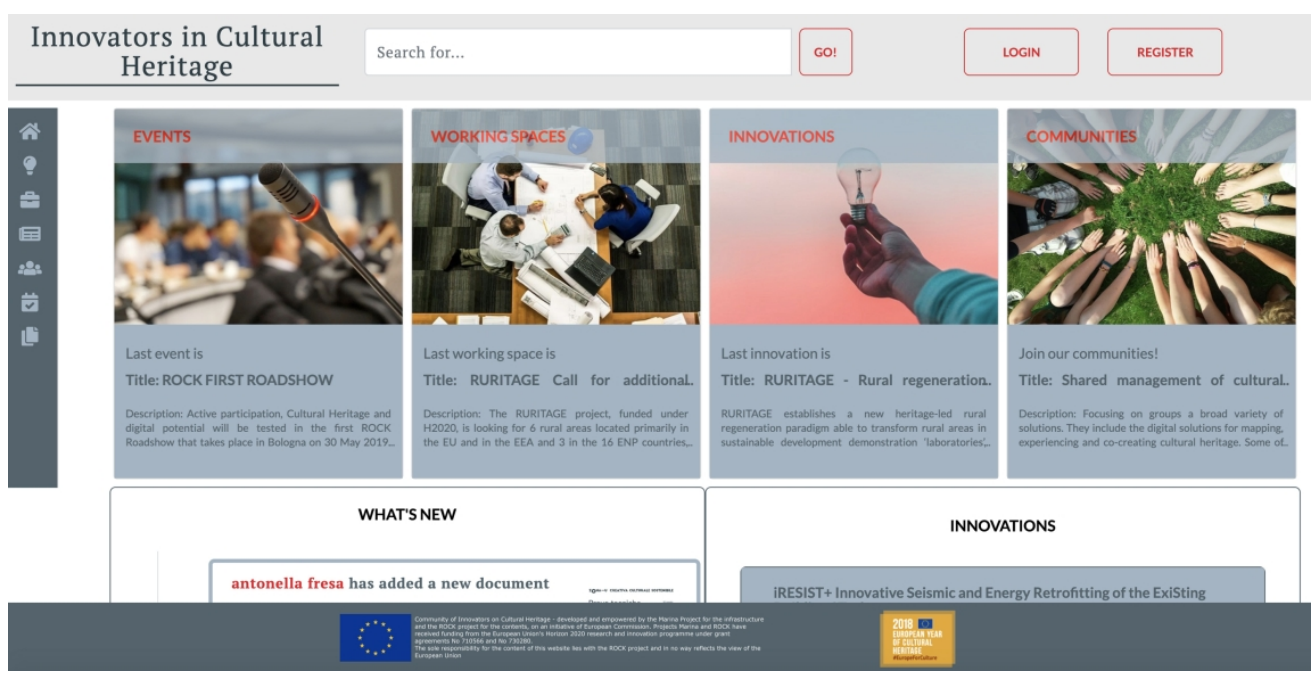

Fig. 11: Home page of the Innovators in Cultural Heritage Platform (www.innovatorsinculturalheritage.eu).

$250 \times 126 \mathrm{~mm}(300 \times 300 \mathrm{DPI})$ 


\title{
ICTs for accessing, understanding and safeguarding Cultural Heritage: the experience of INCEPTION and ROCK H2020 projects
}

\author{
Roberto Di Giulio' ${ }^{1}$, Andrea Boeri², Danila Longo², Valentina Gianfrate ${ }^{2}$, \\ Saveria O.M. Boulanger ${ }^{2}$, Chiara Mariotti ${ }^{2}$ \\ ${ }^{1}$ Department of Architecture, University of Ferrara, Ferrara, Italy \\ ${ }^{2}$ Department of Architecture, University of Bologna, Bologna, Italy
}

Reference person: Roberto Di Giulio, Professor, Department of Architecture, University of Ferrara, Via della Ghiara 36, 44121 Ferrara, Italy. E-mail: roberto.digiulio@unife.it 


\title{
ICTs for accessing, understanding and safeguarding Cultural Heritage: the experience of INCEPTION and ROCK H2020 projects
}

\begin{abstract}
Today digital technologies offer great opportunities in the field of Cultural Heritage $(\mathrm{CH})$. After a general overview of the European policy documents on $\mathrm{CH}$ digitisation, the paper aims to reflect on tools, procedures and methodologies in the use of Information and Communication Technologies (ICTs) as a new way of visualization, application and data collection towards accessing, understanding and safeguarding our historic built environment. The focus will be on two ongoing H2020 project, INCEPTION and ROCK, selected to address the problem of $\mathrm{CH}$ digitisation and the access to the corresponding digitized resources in relation to historic buildings and urban districts. Therefore, they are presented as inspiring good practices for tackling this issue considering its impacts both at the architectural and urban scale. Stressing the potentials of enabling technologies, such as 3D laser surveys, environment and climate sensors, large crowd monitoring tools and $\mathrm{CH}$ analytic, they are also able to orient future research beyond 2020 .
\end{abstract}

Keywords: Cultural Heritage; Information \& Communication Technology; Accessibility; Understanding; Safeguard; H2020; INCEPTION; ROCK.

\section{Introduction}

In line with the conclusions adopted by the Council of Europe in 2014, European polices extensively promoted the centrality of Cultural Heritage $(\mathrm{CH})$ as "a strategic resource for a sustainable Europe" (Council of the European Union 2014, 1). Consequently, the European Union (EU) encouraged researches for the development and the advancement of all instruments needed to promote economic growth, social cohesion and environmental sustainability starting from our tangible and intangible cultural heritage. Instruments and tools that seem to favour new effective ways of accessing, understanding and safeguarding $\mathrm{CH}$ are the Information and Communication Technologies (ICTs). Thus, EU initiatives started to give a key role to the development of new digital 
technologies and to digitisation processes, in unprecedent ways. The result was the definition of a hybrid experimental field that brought together scientific research areas such as computer science, geomatics, restoration and technology for historic architectures and sites, opening new scenarios for the locked-up potential of Europe's $\mathrm{CH}$. The following study was born and developed within this research field.

\section{Objective and Methodology}

The objective of this paper is to analyse the current and most innovative practices of use of digital technologies applied to Cultural Heritage. The aim is to identify some of the most promising strategies and innovation that can boost the valorisation-enhancement and preservation of cultural heritage, considering it both in its material and immaterial nature (Sonkoly and Vahtikari 2018). The integration among different available technologies-it is the key point for innovation in this paper. It is structured in two core sections: the first one offers a general overview of the European policy documents and events addressing $\mathrm{CH}$ digitisation and investigating the most interesting projects, as selected and presented in the last core events about the topic. The second section deepens two European funded projects, INCEPTION (G.A. 665220) and ROCK (G.A. 730280), highlighting their similarities and differences both in their assumptions, approaches and results. The conclusion will identify some red lines and promising roadmaps for the future of the practice.

The paper is based both on a desk research and on the direct research experience on INCEPTION and ROCK projects. The desk research concerns the first section of the paper. The selected projects are the projects presented in the three main meetings and workshops discussing about the topic:-In particular, the "Digital Day” (April 9, 2019), the Brussels Workshop on "Common challenges and perspectives for Digital Cultural 
Heritage in H2020 projects" (November 14, 2018), the Policy Review at the end of the European Year of the Cultural Heritage (EYCH) (January 2018).

\section{Section 1: Cultural Heritage in Digital Era}

\section{European polices on digitisation of Cultural Heritage}

"The digital revolution is leading to new and innovative forms of artistic creation while making culture and heritage more accessible and opening up new ways of enjoying cultural contents. Making our cultural heritage widely available in the digital era is vital" (Ansip, Gabriel, and Navracsics as quoted in European Commission 2019). Today, digital transformation is one of the social, cultural and economicmost pervasive and mediatic phenomena characterizing our era, to the point that we often talk about Digital Era. In parallel, the growing attention to Cultural Heritage as a fundamental key driver of social cohesion, economic and sustainable growth has encouraged the development of enabling technologies for its knowledge, dissemination, reuse, conservation and enhancement across borders. Thus, a close bond has been established between $\mathrm{CH}$ and ICTs, leading the European Union to declare the urgent need to digitalise eulturatheritage for recording, documenting and preserving Europe's eultural-inheritance and even more for fostering its visibility and accessibility, improving the engagingement of -local communities and supporting spill-overs in transversal sectors such as education, tourism, creative and cultural industries.

This is the perspective of the Digital Day 2019-( $3^{\text {rd }}$ edition $)$, the last international event

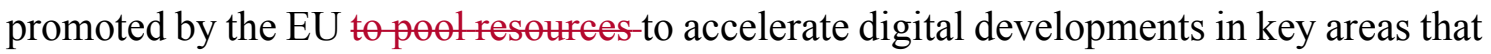
can bring tangible benefits to our economies and societies. On the 9 April 2019, as part of the thematic area dedicated to the $\mathrm{CH}$ digitisation, 24 European countries signed the 
Declaration "Cooperation on advancing digitisation of cultural heritage", which stated: "Emerging technologies such as big data, artificial intelligence and extended reality offer numerous possibilities to further process and use digital cultural heritage. 3D technologies are especially promising, providing new ways of advancing scientific understanding, handling and restoring damaged or fragile heritage and ensuring digital preservation that reflects the uniqueness and multidimensionality of our heritage. $3 \mathrm{D}$ is also one of the foundations for interactive technologies such as virtual and augmented reality for cultural applications" (Declaration: Cooperation on advancing 2019, 2). As a matter of fact, the development and use of digital tools, for example ${ }_{2} 3 \mathrm{D}$ integrated laser scanner- allow to survey rapidly historical buildings and urban-sites by collecting millions of spatial coordinates used for creating 3D models with a high degree of accuracy and precision. The availability of innovative tools, based on 3D models, the Virtual Reality (VR), the Mixed Reality (MR) and the Augmented Reality (AR) open innovative scenarios for Cultural Heritage $\underline{\mathrm{CH}}$. 3D models can be used not only for documentation and monitoring purposes but also for digital applications (e.g. virtual tours, virtual tourism, digital reconstructions, etc.) and for creating integrated 3D database useful for preserving, diagnostic, restore-conservation and management procedures.

In tackling the main challenges related to the so-called " 4 th industrial revolution" and its impact on heultural Heritage, the Declaration highlighted two additional crucial points: the commitment to support the digital transformation of eultural heritage $\underline{\mathrm{CH}}$ institutions and the need to ensure that digitised cultural contents and related applications will be available_, in line whe their values, on appropriate European platforms. In relation to the latter, it is also interesting to stress the effort of economic and business companies to test and improve-advanced technologies for supporting the innovative use of digitalised cultural resources, the knowledge extraction and the more engaging experience of 
heritage contents. For instance, theThe engeing research carried out by Vodafone for the implementation of $5 \mathrm{G}$ technology is a case in point: it performs this task. Presented by Vodafone at the International Conference "Cultural Heritage: challenges, new perspectives and technology innovation. Towards informative content models and beyond" (Milan, 8-10 May 2019), itaims to make available high-quality interlinked data and complex multimodal objects for promoting $\mathrm{CH}$ through narratives and immersive experiences using smart phones and tablets (Baggioni 2019).

However, the matter of $\mathrm{CH}$ digitisation was also one of the core topics discussed during the Symposium "Horizons for Heritage Research. Towards a Cluster on Cultural Heritage", held in Brussels on 20 March 2019, just few days before the Digital Day. The participants shared the intention to constitute a new governance structure addressed to professional stakeholder partners of EU institutions for the co-creation of eultural heritage $\underline{\mathrm{CH}}$ researches and the construction of the innovation agenda of Horizon Europe (Vahtikari 2019). Nevertheless, the most interesting question for this dissertation is that In addition, a specificthe second-session of the symposium was designed to discuss prominent eultural heritage $\underline{\mathrm{CH}}$ themes and that one of them, among the 4 selected, was dedicated to "Digital cultural heritage". Chaired by the Policy Officer Albert Gauthier, the roundtable on this topic made clear the issues of digitisation and accessibility, and it claimed that the "quality instead of quantity of data is a central concern in digitization, so the work should focus on creating quality standards. Also issues of copyright, automatic annotation of objects and the need for a European storage capacity were pointed out as an absolute necessity, as well as curation, which is of key importance for accessibility, interaction, participation and re-use of objects" (Vahtikari 2019, 13). Exactly one year after the high-level conference "Innovation \& Cultural Heritage", the roundtableall participants remembered and sharedstressed the importance of defining an holistic 
approach to heritage and heritage research and concluded that "digital cultural heritage should be seen as part of cultural heritage, not as a separate realm" (Vahtikari 2019, 13).

The great fervour linked with the above-mentionedthese recent events reminds us how much the question of $\mathrm{CH}$ digitisation is current and relevant today; although it should be noted that these are not the only remarkable results. Over the past decade, Member States have significantly invested in digitisation and digital preservation of eultural heritage $\underline{\mathrm{CH}}$ and, as a direct consequence, mainly in the context of digitisation efforts and collaboration at European level (Fig 1). A first milestone was reached with Europeana, the European's digital platform for cultural heritage, funded as a well-established Digital Service Infrastructure under the Connecting Europe Facility (CEF) to bring Europe's digitised eultural heritage $\underline{\mathrm{CH}}$ material online and to promote its cross-border visibility, accessibility and usability across Europe. Launched in 2008, it currently provides access to over 51 million items from the collections of over 3700 European libraries, archives, museums, galleries through its main portal Europeana Collections and through the platform's Application Programming Interfaces (APIs) (European Commission 2018a). At the beginning of 2019, Europeana published an Innovation Agenda that highlighteds research and innovation priorities in the eultural-heritage domain-and advocates for their implementation across Europe. According to the Europeana Network Association, the Agenda listed 13 topies that showcase the opportmities of transformation in 4 overarching categories and, once again,_and, once again, one of them wasis "Technological innovation". After stating that "the Europeana Innovation Agenda aims to ensure long-term access to cultural assets and calls for continuous support for the improvement of digital content, tools and services offered by cultural heritage organisations" (Oomen and Bočytè 2019, 8), the document pointeds out 5 specific topics for this eategory-priority including digitisation and digital durability (1), 
digging into data (2), data quality, usability and retrieval (3), infrastructures for secure, trustable and shareable content (4) and storytelling and immersive experiences (5). In particular, with regardrelation to this last objective, the Agenda confirmeds that "research actions should focus on unleashing the potential of novel technologies such as VR, AR, 360 videos and 3D modelling to offer full-body, immersive and personal encounters with cultural heritage" (Oomen and Bočytė 2019, 10).

After thatBesidesSoon after the construction of Europeana, in 2010, a new goal was achieved with the launch of the Digital Agenda for Europe. Planned as one of the 7 flagship initiatives of the Europe 2020 Strategy, it aims to-defined the key-enabling role that the use of ICTs will play if Europe wants to succeed in its ambitions for 2020. As stated in the documents, the more effective-use of digital technologiesICTs "will provide Europeans with a better quality of life through, for example, better health care, safer and more efficient transport solutions, cleaner environment, new media opportunities and easier access to public services and cultural content" (European Commission 2010, 3). Then in 2011, under the Digital Agenda for Europe, the report "The New Renaissance" by the Comité des Sages on bringing Europe's cultural heritage online (Comité des sages 2011) and the "Commission Recommendation on the digitisation and online accessibility of cultural material and digital preservation" (European Commission 2011) were published in order to help cultural institutions make the transition towards the digital era_and-improving the conditions for the entire digitisation lifecycle (Comité des sages 2011 ; European Commission 2011).

At the same time, the EU Work Plan for Culture (2015-2018) also raised the importance of the interaction between tangible, intangible and digital cultural heritage. Since digitat technologiesICTs have changed the way people access, produce and use cultural content, the EU Work Plan for Culture paid specific attention to "digital shift challenges" 
exploring "how digitisation of cultural content and digital services can foster the expansion of trans-European tourism networks" (European Commission 2014, 5, 11).

In a global perspective but with the same assumptions, the 2030 Agenda for Sustainable Development, adopted by all United Nations Member States in 2015, encouraged the advance and implementation of ICTs to speed up progress towards each one of the $\mathbf{1 7}$ Sustainable Development Goals-(SDGs). In the opening paragraph about "Our world today", $\mathrm{t}$ The Agenda declared that "the spread of information and communications technology and global interconnectedness has great potential to accelerate human progress, to bridge the digital divide and to develop knowledge societies, as does scientific and technological innovation" (United Nations 2015, point $\left.n^{\circ} 15\right)$.

Another significant breakthrough on digitisation for $\mathrm{CH}$ promotion and preservation was recorded in 2018, when the EU decided to dedicate the year to the Cultural Heritage = that was the European Year of Cultural Heritage - fostering the launch of specific policies and projects on the topic. The EU decision proved how Cultural Heritage $\underline{\mathrm{CH}}$ could effectively conceptualise global cultural challenges and have impact on society, economy and environment. In this context, new scenarios have been opened up especially thanks to digital technologies. Therefore, to make the impact of digitisation more effective - in terms of innovative forms of artistic creation, more democratic access to heritage $\underline{\mathrm{CH}}$, and new ways to enhance and monetise cultural content - the New European Agenda for Culture defined the "Digital4Culture" strategy. Its core objective was to "create a network of competence centres across the EU to safeguard knowledge of endangered heritage monuments through large-scale digitisation [...], set up a panEuropean network of Digital Creative and Innovation Hubs to support digital transformation, propose next steps for Europeana [...], stimulate cross-overs and collaboration between art and technology for sustainable innovation on industrial and 
societal levels" (European Commission 2018b, 9).

In some waysAdditionally, the position paper on the European Research Policy for Cultural Heritage written by Gábor Sonkoly and Tanja Vahtikari offered an extra point of view on this subject. Entitled "Innovation in Cultural Heritage Research" and published at the beginning of the European Year of Cultural HeritageEYCH, it recognized that "the integrated definition of cultural heritage requires not only a new conceptualization, but also a new techniques and practices between the wide range of concerned participating communities and individuals" (Sonkoly and Vahtikari 2018, 37). In deepening this matter, the authors stated that if digitalisation "seems to be most obvious instrument of democratisation of cultural heritage", however, "the digital divide has mixed existing and new forms of exclusion" (Sonkoly and Vahtikari 2018, 38). Similar considerations lead Sonkoly and Vahtikari to stress the idea that "the use of digital heritage by the different social, cultural and professional groups calls for research, which takes into consideration the social effects of virtual realities and the visibility of actorship in the processes related to cultural heritage practices" (Sonkoly and Vahtikari 2018, 38).

Criticality and potentials of digitisation are also underlined during the Conference “Innovation \& Cultural Heritage", held in Brussels on 20 March 2018. Here once again, Professor Gábor Sonkoly of the Eötvös Loránd University in Budapest urged researchers to handle digital technology critically, as he said, "it could lead to extreme individualisation, the opposite of community-building" (Sonkoly as quoted in Collins 2018).

Reflections on impacts of heritage $\underline{\mathrm{CH}}$ digitisation moved on also during the Workshop "Common challenges and perspectives for Digital Cultural Heritage in $\mathbf{H 2 0 2 0}$ projects", organized in Brussels by the Research Executive Agency on 14 November 
2018:- Seven 7 ongoing Herizen 2020 projects in the field of digital $\mathrm{CH}$ were invited and shortly presented in order to better orient future researches. Concluding remarks were focused on the importance to "continue to build on digital for cultural heritage with particular emphasis on promising technologies such as 3D, Virtual Reality, Augmented Reality and Artificial Intelligence" as well as to support the construction of build an "European platform on cultural heritage preservation and conservation using digital technologies" (Tsakou and Athens 2018).

Starting from the results of the EYCH and ensuring its legacy for developing further concrete activities, the European Framework for Action on Cultural Heritage was programmed and launched at the end of the year. Announced in the New European Agenda for Culture and designed to support actions beyond 2020, it promoted and put in practice a holistic and participatory approach to $\mathrm{CH}$ focusing on 5 main pillars. Under Tthe pillar 4, "Cultural Heritage for an Innovative Europe", it emphasised the digital dimension of $\mathrm{CH}$-stating:-; "Digital technologies offer unprecedented opportunities for us to improve public access to cultural heritage assets and allow for their curation and reuse. Innovative technologies, such as virtual or augmented reality, can also enhance people's experiences with cultural heritage, while digital tools such as 3D scanning play a major role in the preservation and restoration of physical heritage assets" (European Commission 2018c, 8).

The attention paid by the new European action plan to the matter of $\mathrm{CH}$ re-use wasis ats directly connectedin line with the acquisitions of the contemporary-Leeuwarden Declaration on "Adaptive re-use of the built heritage: preserving and enhancing the values of our built Heritage for future generation", adopted on 23 November 2018. Taking stock of lessons learned over the EYCH and reflecting on good practices for quality interventions, the Declarationit remarked the potentials of $\underline{\mathrm{CH}}$ digitalisation for 
the preservation and construction of tangible and intangible values linked with our inheritance: - In this perspective, it affirmed, "good story-telling, using all opportunities offered by digital technologies, is key to conveying the history of the place and enhancing its heritage value" (Leeuwarden Declaration 2018).

Finally, this overview on the Europe's involvement in the field of digital $\mathrm{CH}$ cannot exclude a focus on practical experimentations (Fig. 2). Taking input from the EU-funded project already implemented, sharing their knowledge and building added value is what really matters today. Future researches will be based on the experiences carried out during the $\mathrm{EYCH}$ and on their major results, both positive and negative. As pointed out during the Symposium mentioned at the beginning of this paragraph, EU actions for future will be divided in 5 key areas. One of them will be on "Mobilising knowledge and research as a way to support advanced digitisation and foster social innovation". The European Union will invest 265 million euro for this thematic area. The digitisation of Cultural Heritage in relation of its multi-level nature (tangible and intangible) and multi-scalar dimension (architectural, urban and territorial) is still an open challenge.

\section{Cultural Heritage and ICTs: a new alliance. A high-quality selection of EU projects on digital $\mathrm{CH}$}

The first paragraph highlighted how nowadays the link between digital technologies and cultural heritage is perceived necessary for the future of the mankind and its inheritance. Mainly focused on the European level, the paper showed up the major moments and manifestos that are framing this new context of research, policies and innovation. However, when speaking about Information and Communication TechnologiesICTs applied to cultural heritage it is possible to find several examples both on technologies and on objects of application. This study stresses this relation analysing some key 
European projects presented in the last three core events on digital $\mathrm{CH}$ that are contributing in relevant way in framing the topic. The following figures figure 3-resumes the analysed projects, identifying the used digital approaches (Fig. 3) and . Hence, figure 4 resumes the analysed projects details, including a short description (Fig. 4).

Through this analysis, some common approaches can be identified. At first, each project focuses on different research objects. As, in fact, it is highlighted into the "Innovation in Cultural Heritage Research” report (Sonkoly and Vahtikari 2018), cultural heritage can be intended in very different ways, material and immaterial. According with the 19 analysed projects four are the most common objects of the research:

- single objects/architectures that are subject of $3 \mathrm{D}$ reconstruction, as in the case of INCEPTION and iMareCulture;

- projects that work on immaterial $\mathrm{CH}$, such as PLUGGY that works on cultural stakeholders, TROMPA working with musical heritage involving stakeholders, CoHERE, CULTURAL BASE, EUNAMUS, PERCEIVE, RICHES, SIGN-HUB;

- projects that work on capacity building in Europe, and/or with citizens, stakeholders, communities of practices on material and immaterial $\mathrm{CH}$, such as COHESIFY, COURAGE and PERCEIVE;

- finally, projects concerning documentation materials, archives or museum collections, as in the case of ViMM and EMOTIVE, NewsEye, COURAGE, SIGN-HUB and SILKNOW.

As happens with the objects of each research, also objectives are different. Therefore, it is possible to identify some common lines as following: 
- reconstruction of $\mathrm{CH}$ elements in 3D for enhancing the research capacity and increase the academia and stakeholders' knowledge for the present and future researches, as in the case of INCEPTION, GRAVITATE, Time Machine;

- projects that aims to reconstruct $\mathrm{CH}$ in $3 \mathrm{D}$ or digitize it in order to guarantee their preservation for future generations or to allow their universal access, including the enhancement of touristic applications, as in the case of INCEPTION, iMareCulture, Time Machine, EMOTIVE, NewsEye, SILKNOW, EUNAMUS, SIGN-HUB;

- projects that aims to create unconventional narratives and storytelling, to increase of communities/stakeholders' capacity building, as in the case of iMareCulture, Time Machine, ViMM, EMOTIVE, SILKNOW, CoHERE, COHESIFY, COURAGE, CULTURAL BASE, PERCEIVE, RICHES, SIGN-HUB;

- finally, projects that aims to create new virtual communities and to foster the creation of new collaborations among stakeholders, as PLUGGY, TROMPA, CULTURAL BASE.

Even if these approaches can seem very different, both for object and objectives, there are some common enabling technologies that are frequently used in most of the listed experiences. In fact, the digitalization of the society and the availability of innovative tools and instruments are highly helping the research on $\mathrm{CH}$ in reaching new objectives and new possibilities, even when applied to very different cases. According with the conducted analyses, six four types of innovative enabling technologies can be recognised:

- one of the most used approach is the 3D reconstruction of specific $\mathrm{CH}$ objects. This technique foresees the use of laser-scanners, innovative cameras and videomapping, 
both static or dynamic (e.g. those installed on drones). This technology is necessary for the digitization of objects, such as architectures, damaged heritage (e.g. ancient books, artefacts) etc. These tools are fundamental for creating shareable and questionable-questioning digital repositories, useful for different purposes (research, restauration/conservation, education, tourism, etc);

- Semantic, taxonomy and open access. Even if they are not strictly digital technologies, a great attention is nowadays given to open access, semantic and taxonomy as ways to involve researchers, stakeholders outside the project consortium, but also the community of European citizens that can have interest in accessing research data and results. In particular, the use of open access both for publication and research data is recommended by the European Commission (European Commission 2012). For researches on $\mathrm{CH}$, the open access seems to be a current and common trend, as $\mathrm{CH}$ is for definition a shared community inheritance. Thus, its accessibility to everyone is of particular interest. In fact, most part of the projects are designing open access platforms where the digitization of $\mathrm{CH}$ elements can be not only shared with the public, but also be a meaning of education, interplay and engagement. As, for example, it happens in projects such as COHESIFY, COURAGE, CULTURAL BASE, PERCEIVE that foresee the use of gaming experience, innovative learning methods and interactions with the society. The theme of making $\mathrm{CH}$ available in open access formats poses immediately the question of multi-languages. The presence of multiple ways to identify specific $\mathrm{CH}$ elements, artefacts or parts of them, as well as the presence of multiple and different languages in Europe and technical vocabulary can pose several risks and cause challenges when multiple sources become accessible to everyone. Thus, the accessibility and the shareability of similar databases rely on the use of a common vocabulary, shared among all. As a matter of fact, several 
international agencies are providing similar contents. This usually goes under the name of Thesaurus (UNESCO, Getty, etc.). Several projects, such as INCEPTION, are strictly working with these instruments in order to share their use and to contribute into its advance;

- Immersive Virtual and Augmented Reality experiences and Gaming applications. Both technologies are based on the possibility to include citizens and potential different targets of people into an immersive environment reconstructing, in many different ways, a past, even no more existing or fictional environment. As defined by Chavan S. (2016), augmented reality is a view of an environment where some elements are augmented with images, sounds or additional information, while virtual reality is a complete, immersive and totally artificial reconstruction. iMareCulture, ViMM, EMOTIVE projects propose virtual realities. Also Gaming applications are becoming common applications for $\mathrm{CH}$. In addition to the previous technologies, they include an interactive component and they are particularly used for education and teaching purposes;

- Some projects, such as iMareCulture, propose 3D printing as a major innovation. The digitization of $\mathrm{CH}$ artefacts and components allows, in fact, to share 3D models that can be compatible with home $3 \mathrm{D}$ printing. This approach ensures a full experience of accessibility, giving the opportunity to print historical and artistic elements at home.

These types of enabling technologies seems to beare the most innovative and used ones in the selected projects. In addition to them, the most common digital platform, as repositories of information, 3D models and applications are also particularly spread. The most innovative ones allow not only to share information and data, but also to interact in multi-modal ways (e.g. create personalized analysis from available data or insert new 
persenal-data) or to be the base for community creation. The described technologies are available in the market in many forms since years. Even if some specific advances are undertaken by each project, the main innovation relies on the integration of different technologies together. In fact, the previous analysis also highlighted how no projects can be categorized in only one single thematic subdivision. This point is crucial when speaking about innovation in technologies applied to $\mathrm{CH}$ : it is perceived by the authors that the red lines behind all these approaches is the way in which the different components are put together and combined in unconventional ways.

This paragraph identified some common and innovative approaches, in a selection of recognised innovative projects. Next section will deepen two projects, identifying their approach in using digital technologies applied tofor $\mathrm{CH}$ and focusing on the different ways in which they are combined together.

\section{Section 2: INCEPTION and ROCK H2020 project}

Starting from the analysis conducted in the previous section regarding the connection between $\mathrm{CH}$ and digital technologiesICTs in a selection of outstanding EU-funded projects, this further section will investigate more deeply two projects that are, in different ways, using technologies applied to cultural heritage. Both projects have the objective to enhance while preserving $\mathrm{CH}$ even if they work on different scales. INCEPTION works on the 3D reconstruction of single historic artefacts, mainly architectures, while ROCK works on the application of technologies for urban districts in historic city centres. The results will deepen these distinctions and similarities, with the aim to discuss the potential of ICTs for the better knowledge, use, management, conservation and enhancement of 
$\mathrm{CH}$ and identifying some orientations for a roadmap for European cities.

\section{INCEPTION project. $\mathrm{CH}$ digitisation at the architectural scale}

The INCEPTION project - Inclusive Cultural Heritage in Europe through 3D semantic modelling - (G.A. 665220) was funded under the Horizon 2020 Programme, Work Programme "Europe in a changing world - inclusive, innovative and reflective societies", topic "Reflective Societies: Cultural Heritage and European Identities", call "REFLECTIVE 7-2014: Advanced 3D modelling for accessing and understanding European cultural assets". Ranked first of 87 RIA (Research and Innovation Action) proposals, the project boasts a consortium of 14 partners from 10 European countries under the coordination of the University of Ferrara, Italy (scientific coordinator: Professor Roberto Di Giulio). The EU contribution of 3.990.205 EUR supports a four-year project, started in June 2015 and it will end in May 2019 (European Commission 2018d, 71-72; INCEPTION Official Website).

INCEPTION develops innovation in cultural heritage 3D modelling through an inclusive approach for time-dynamic 3D reconstruction of artefacts, mainly historic architectures, sites and social environments (European Commission 2018d, 71). INCEPTION main goal is to overcome the limits of state-of-the-art 3D reconstruction, by significantly progressing functionalities, capabilities and cost-effectiveness of instruments and deployment procedures for 3D laser survey, data acquisition and processing (INCEPTION Official Website) (Fig. 5). According to its vision, it aims to create an open-standard Semantic Web platform for accessing, processing and sharing interoperable digital models resulting from 3D survey and data capturing (INCEPTION Official Website). The relevance of this research was recently confirmed during the above-mentioned Digital Day: INCEPTION was presented as the first ongoing H2020 
project in a high-quality selection of $5 \mathrm{EU}$ researches in field of digital cultural heritage (European Commission 2019). After all, the study has demonstrated to take on board all the European Community's assumptions and challenges on digitisation, ensuring a further step forward on this topic.

Starting from the idea that $\mathrm{CH}$ documentation is essential to understand and give value to our cultural legacy, INCEPTION tests advanced ICTs to createfor multi-layered knowledge databases using laser scanner applications. Thanks to the automatic acquisition of geometric parameters, it experiments the creation of high-definition threedimensional morphometric archives where data can be collected not only on shape and dimensions, the so-called "geometric memory", but also on topography, materials, structures, state of conservation, diagnostic analysis, historic facts related to the detected object (Maietti et al. 2017). The result wants to beis " the holistic heritage documentation, the semantic enrichment via $3 \mathrm{D}$ modelling in $\mathrm{H}-\mathrm{BIM}$ environment, and the models deployment and valorisation through the INCEPTION platform" (Maietti et al. 2018므, 357).

By defining an open-standard format and semantic ontology to generate high-quality and interoperable models of Heritage Building Information Model (H-BIM) (INCEPTION Official Website), INCEPTION intends to supports process of management, maintenance, conservation, and enhancement of heritage sites encouraging the use of such collected data - in this way exportable, updatable and implementable - by all relevant categories of users interested in $\mathrm{CH}$ research and thus facilitating transdisciplinary collaborations.

Compared to the many ongoing and already ended projects on $\mathrm{CH}$ digitisation, INCEPTION differs because it focuses on "heritage 'spaces"” (Maietti et al. 201 $\underline{\text { b }}$, , 357) 
and, as it is well known, spatial cultural assets, such as historic buildings, are often characterized by unconventional location, features and geometries. Working on 3D survey of these spaces means to investigate and control the binomials space/time, space/user and space/identity: in fact, historic architectural spaces have always changed over time, but despite this they have always established new and renewed interfaces with users - today on-site and off-site users - and, last but not least, they have been able to build an evolving identity still rooted in the memory of places.

Assuming these implications as a starting point, INCEPTION applies the described process on 9 demonstration cases across Europe, selected from 6 partner countries (INCEPTION Official Website) (Fig. 6): Istituto degli Innocenti (Florence, Italy), Historic church of Obergum (Groningen, The Netherlands), Castillo de Torrelobatón (Valladolid, Spain), Cultural Heritage Municipality of Unešić (Unešić, Croatia), Technical Museum Nikola Tesla (Zagreb, Croatia), Church Panayia Phorviotissa (Asinou), Nikitari village (Troodos, Cyprus), The Akropolis of Erimokastro (Rhodes, Greece), Villa Klonaridi (Athens, Greece) and the HAMH Museum (Hydra, Greece).

The wide spectrum of spatial contexts offered by pilot sites allows to verify the project methodology in relation with the complexity and the heterogeneity of built heritage at the architectural scale. As a matter of fact, the 9 buildings have different typologies and use vocations (churches, castles, villas, palaces, museums and archaeological sites), spatial configurations and dimensions (from single architectures to delimited urban areas); they were also built in different historic periods (from ancient times to the present day), they show various states of conservation (ruins, partially lost or intact architectures) as well as peculiar connections with the surrounding context (urban or natural setting). Finally, they have diverse tourism relevance in their respective countries (national monuments or 
abandoned places), condition that makes them potential catalysts of attractiveness thanks to the use of advanced 3D model technology.

In order to create a semantic H-BIM for all demonstrative cases, the first step is defining an ontology, intended as a set of concepts within the cultural heritage domain based on a specific language denoting properties and interrelations for $\mathrm{CH}$ (Maietti et al. 2018 $\underline{\mathrm{a}}, 2$ ). Nevertheless, building a language to name every single element of historical architectures is not an easy exercise: in fact, each building is the final result of a complex diachronic process in which construction techniques, availability of materials, decorative apparatus, but also transformative needs and uses played a fundamental role. For this reason, That's why each historical building reveals a uniquenessis unique and that hardly fits into a standard dictionary.

To meet the double requirement of not reducing $\mathrm{CH}$ complexity and of setting up a sharable $\mathrm{CH}$ language code, INCEPTION designs a common glossary for the semantic enrichment and modelling in BIM environment, and organises names according to a structure that could ensure the relation between the elements and their subsequent reuse in the IT development phase (Logothetis, Delinasiou, and Stylianidis 2015, 177). After an in-depth analysis of the many languages already developed to collect information on cultural heritage (Herein, UNESCO Thesaurus, UK Archival Thesaurus, Pactols Thesaurus, Getty Art \& Architecture Thesaurus, to name the majormain ones), the project recognises the importance to connect data in a dynamic version using a Semantic Web technology and Linked Open Data principles that make it possible to define an open HBIM ontology without defining the complete schema as a copy of external sources. The INCEPTION strategy aims to extend the H-BIM ontology based on the classification available in Getty, integrating this with the BIM classification generated from the IFC (Industry Foundation Classes) schemas (Maietti et al. 2018ㅁa, 5-6) (Fig. 7). 
Up to now, the method for supporting the semantic approach to $\mathrm{CH}$ has been defined and a preliminary nomenclature for 3D model enrichment has been developed. Being the integration of semantic $3 \mathrm{D}$ reconstructions with intangible information and social environment another priority of the project, it has been tested the upload of additional contents to the platform (e.g. VR and AR) for each demonstration-of 9 case (Fig. 8). INCEPTION platform has been gradually populated using these first results; in this perspective, its validity and efficiency could be verified as a significant dissemination tool.

Thanks to this advanced digital tool, experts will be able to visualise, update, manage and exchange data and metadata semantically organized, while non-experts access to various information related to the building (history, transformation over the centuries, etc.). Digital or digitalised contents (technical or educational ones) linked to 3D H-BIM models will support a more accessible and sharable cultural heritage for all.

According to the Faro Convention, the project has proven to encourage the creation of "a heritage community consists of people who value specific aspects of cultural heritage which they wish, within the framework of public action, to sustain and transmit to future generations" (Council of Europe 2005). Last but not least, INCEPTION seems to responds to Jukka Jokilehto's call to consider CH "both in time and in space" (2005): by layering different information directly connected to spatial coordinates, the research allows heritage community to manage contextually space and time dimension of historic buildings. On the one hand people could know the past using, for example, the $3 \mathrm{D}$ virtual application that shown the building reconstruction in different eras, on the other one preserve the future in the present using, for instance, 3D laser scanner survey for designing restoration works or prevented and planned conservation programmes. 


\section{ROCK project. $\mathrm{CH}$ digitisation at the urban scale}

ROCK stands for Regeneration and Optimisation of Cultural heritage in creative and Knowledge cities. The project (G.A. 730280) was ranked first in the Horizon 2020 Programme, Work Programme "Climate action, environment, resource efficiency and raw materials", topic "Cultural heritage for sustainable growth", call "SC5-21-20162017: Cultural heritage as a driver for sustainable growth”. Design as an IA (Innovation Action), it obtained an EU contribution of 9.873.585 EUR and it will last three years, from June 2017 to May 2020. The project involves 32 partners from 13 European countries whose synergic commitment is under the coordination of the Municipality of Bologna, Italy (European Commission 2018d, 35-36; ROCK Official Website).

ROCK develops innovation in cultural heritage through an innovative, collaborative and systemic approach that promote $\mathrm{CH}$-led regeneration strategies for historic city centres. Starting from the selection of three demo areas afflicted by physical decay, social conflicts and poor life quality (Bologna, Lisbon and Skopje), it supports their transformation into Creative and Sustainable Districts through a shared generation of new sustainable environmental, social, economic processes (ROCK Official Website) (Fig. 9).

Compared to ongoing projects on $\mathrm{CH}$, ROCK differs because it focuses on heritage urban space, notably urban spaces characterized by the presence of important cultural heritage, both material and immaterial. ROCK approach foresees the identification of strategies of regeneration that involves not only project partners, researchers and policy makers, but also citizens and local stakeholders, with the aim to co-design shareable and more effective strategies. Thus, the role of digital technologies is crucial inside the project, as they give a unique potentiality in involving citizens, acquire new and deep knowledge on social behaviours, as well as aequire deep knowledge on the built environment 
complexity. Their role is not only in the application of single or standing alone devices, but in crossing results and potentialities among them in order to find unconventional strategies to face urban challenges. As a matter of fact, ROCK needs to face the multilayered complexity of urban spaces and, moreover, of historical city centres that have technical, social and economic constraints (Boeri et al. 2019; Gaspari, Boulanger, and Antonini 2017). Therefore, the project foresees the implementation of enabling digital technologies for supporting cultural heritage-led regeneration strategies. According with the dynamic and the multi-layered complexity of urban spaces, the project is implementing a coordinated and complimentary panel of technologies, as following:

- ROCK Web Platform. An interoperable platform that collects and manage projects and cities datasets;

- Augmented Reality in the form of a multiplatform app for smartphones and tablets;

- An integrated cultural heritage analytics, which is the combination of Opinion Analytics with Video Neuroanalytics and a range of intelligent decision support systems (this tool has been selected for the Fair of Innovators in Bruxelles, 2019);

- Large crowd monitoring tool. A LBASense system to measure over time data on activities and mobility patterns;

- Outdoor multi-parameter. An integrated system of climatic sensors for analysis temperature, wind speed and humidity;

- Outdoor thermal comfort system composed by a simulation software and anonym questionnaires for analysis people comfort in open spaces;

- Indoor microclimate monitoring based on indoor sensors;

- People flow analytics, based on GPS sensors performing location-base analytics on mobility and volunteers preferred paths. 
All the listed technologies are part of an integrated system applied to the material and immaterial cultural heritage of 10 European Cities. Three of them are Replicator Cities (Bologna, Skopje, Lisbon), adapting actions that were considered successful in seven Role Models (Turin, Vilnius, Athens, Liverpool, Eindhoven, Cluj-Napoca, Lyon). This wide spectrum of historical city centres allows the project to test and learn from several approaches, both on the technical and social point of view. In fact, each city has different typologies of city centres from often multi-layered different ages (archaeological, modern, contemporary) with several social compositions (from Jewish communities, to students, to residents, to tourists).

The project innovation onThe project innovation lies not only into the application of different innovative technologies, as a summation of devices, but more en-into their interrelations in describing the complexity of historical city centres and in supporting the transition toward Creative and Sustainable Districts. In fact, ROCK is defining complementary sets of actions according with three major themes: accessibility, environmental sustainability and-new collaborations among stakeholders, environmental sustainability and accessibility. These three pillars have been selected after one year of the project according with the results of Living Labs, participatory approaches and stakeholders' meetings. The themes follow the results of the Innovation in Cultural Heritage Research, as well as the Faro Convention and UNESCO reports, as they address both material and immaterial $\mathrm{CH}$ and they go through the objective of open science and

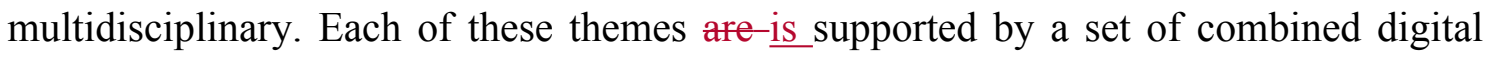
technologies that, with physical and concrete actions, compose a complete scenario of intervention on historical urban spaces.

The first scenario is the creation of new paths for boosting new collaborations among local and international stakeholders. On the digital point of view, this scenario is 
supported by three digital frameworks: ROCK interoperable platform, ROCK Atlas and the Platform of $\mathbf{C H}$ Innovators. The first one is developed directly by the project and it allows the management of several sources of data in order to perform data-based analysis and comparisons. The second one, ROCK Atlas, is also developed entirely inside the project and it is useful for the geographic referencing of ROCK actions, both tangible and intangible (Fig. 10). Each action is in fact recorded into the platform on a city map composed by several layers of detail. End-users can select which layers they want to visualize according with their need. Each action, then, is enriched with factsheet including historical, social, logistic information. The third one is developed in collaboration with MARINA project on an initiative of the European Commission (www.innovatorsinculturalheritage.eu) (Fig.11). This platform is of particular interest for the purpose of this paper as it embodies the creation of a virtual community of international stakeholders working on and dealing with cultural heritage. The platform allows to share information on projects but also to share reports, documents, datasets, events and to create networking and job opportunities. Thus, it creates a prolific environment for sharing innovations: the technology provides a support for the creation of an effective virtual heritage community, according to the Faro Convention. Each of the three Replicator Cities is then using some of the available digital technologies to support the achievement of this objective. In particular, the city of Bologna is developing a gaming experience in the form of a call for creative entrepreneurs. The gaming experience is applied to the museums' collections in the demonstrating area. This approach will not only increase the accessibility of local museums in an immersive and innovative way, but also it increases the collaborations with the local creative industry and entrepreneurs. 
For the environmental sustainability scenario, ROCK proposes the composition of knowledge acquisition on built environment and micro-climate (microclimatic sensors) combined with outdoor project-based simulation through a 2D and 3D software (Envimet). The combination of these two technologies allows decision makers to identify in the specific environment and in the specific selected area which are the best design solutions to be applied. An additional interesting approach is the one provided by the indoor microclimatic analysis. In the city of Bologna, as an example, the system of sensors is applied inside the University Library (BUB - Biblioteca Universitaria Bologna) where some key ancient books are stored and preserved. Here, ${ }_{2}$ sensors are applied in one of the ancient rooms of the library. Thus, the system of sensors-: they allows to acquire knowledge on the indoor microclimatic conditions when the historical room is empty or full or persons and to identify the best strategies for preserving while valorising enhancing the library heritage. The sustainability scenario also allows to boost the interrelations of results coming from the system of sensors, especially from crossing 3D outdoor microclimatic simulations, with large crowd monitoring tools mapping the presence of people in such spaces, with microclimatic sensors mapping wind speed, air pollution, temperature and humidity.

Finally, for the accessibility scenario, ROCK proposes the composition of knowledge acquisition on citizens behavior in their use of indoor and outdoor heritage spaces (GPS trackers used in volunteers' campaigns of mapping, large crowd monitoring) with the creation of applications allowing citizens to access $\mathrm{CH}$ in different ways (virtual reality). In the city of Bologna, virtual reality allows in particularlet citizens to perform a universal accessibility toef $\mathrm{CH}$ by citizens, even if they arealse affected by permanent or temporary disabilities (deaf, blind, motor disabilities). In the city of Skopje, this tool is used for giving new life to the lost Jewish district: In this case, the city is implementing the 3D 
reconstruction of the neighborhood in order to allows help citizens to recover this historical memory.

As highlighted by the description of the three scenarios, the project is using the methodology of research-action-research. Thus, digital tools are really used as enabling instruments that, combined among them and with material and immaterial actions can boost the creation of new values and the reaffirmation of existing ones.

\section{Conclusion}

Thise paper investigated several key EU documents and moments on digital technologies applied to cultural heritage and it analysed some of the most innovative projects working on this topic, as recognised by the European Commission. The paper highlighted some of the most used digital toolsICTs actually used in these projects. Then, it investigated in depth two projects, INCEPTION and ROCK. Both projects work on cultural heritage using different typologies of digital tools with similar objectives but very different approaches and scales. In particular, INCEPTION mainly works on single artefacts of $\mathrm{CH}$ and it applies digital tools in a sub sequential way (starting from digitization in $3 \mathrm{D}$ and ending with the application of additional information and features through a semantically organized taxonomy), while ROCK works on historical city centres, with their multilayered and dynamic complexity and using enabling technologies as collaborative instruments for performing and identifying new strategies for $\underline{\mathrm{CH}-\mathrm{led}}$ urban regeneration.

According with this analysis, it seems-turns out that digital technologies can be applied in very different ways, according with the specificities of research objects, objectives and context of application. Nevertheless, it seems evident that the most innovative approaches tend to involve several tools in a collaborative and interrelated way, instead of a 
summation of single elements. In fact, the current market is already full of very different tools and devices that can of course be improved in a standing alone way but that give the best opportunities when integrated together on a smart city perspective; $\mathrm{CH}$ can benefit more from these interrelations instead of from the implementation of singles devices. This is the case for bothshowed by ROCK and INCEPTION. The first one selects variable sets of digital tools for achieving high objectives of recenstruction discovery and construction of cultural and social values in historical city centres, while the second one uses digital tools with increasing complexity into the description of $\mathrm{CH}$ artefacts and architectures. As a matter of fact, the paper shows how digital technologies applied to cultural heritage can trigger a variety of innovations both in knowledge increase, in $\mathrm{CH}$ accessibility, in use and proactive use by citizens_-, in line with Faro Convention and the Innovation in Cultural Heritage Research) and in improving mitigation and adaptation strategies to climate change.-

The major innovation that seems necessary for the advance of researches on this topic is the creation of a Roadmap for digital tools applied to cultural heritage and paths for integration. A similar document will give experts a framework on innovative ways to intervene on inheritance $\underline{\mathrm{CH}}$, facilitating the selection of solutions according with objects of interventions, objectives and contexts of applications. According to this proposition, some specific innovative lines can be identified. The first one is the potentiality of applying semantic languages and a shared taxonomy to digitized materials (3D reconstructions as well as digitize libraries and archives). The addition of a shared and codified language as well as other information, can simplify the accessibility and shareriness of such digital objects, but also it can simplify the process of digitization when it is not necessary to have a very precise reconstruction of each element, especially when they include very complex decorative details. Therefore, semantic can also be applied to 
intangible cultural heritage. As an example, the ROCK Atlas should be significantly improved with semantic.

The second very interesting innovation is the definition of a collaborative sets of digital tools for enhancing the universal accessibility of $\mathrm{CH}$ in a multi-dimension perspective. Augmented and virtual reality with gaming application and $3 \mathrm{D}$ printing can provide a multi-purpose and multi-target accessibility, allowing new strategies of restauration - conservation and/or research but also allowing innovative methods of learning and education for everybody, including people with disabilities.

The third innovation is the use of digital platforms with the specific aim to create effective virtual heritage communities. These communities can be necessary for sharing methods of interventions, but also for co-designing solutions with new stakeholders. The enhancement of uncommon collaboration of stakeholders is a significant objective in order to advance into the topic and to increase responsibilities towards Cultural Heritage.- 


\section{Figure captions}

Fig. 1: Recent main events in the field of $\mathrm{CH}$ digitisation across Europe. (Design by Chiara Mariotti).

Fig. 2: Timeline of $\mathrm{CH}$ digitisation across Europe (Design by Chiara Mariotti).

Fig. 3: Analyses of digital approaches of 19 selected projects (Design by Saveria O.M. Boulanger).

Fig. 4: Short description of the selected projects (Design by Saveria O.M. Boulanger).

Fig. 5: INCEPTION, 3D survey of Palazzo Arese Litta, Milan, as an example of complex architectural space detected (survey and modelling by DIAPReM Center, Department of Architecture, University of Ferrara).

Fig. 6: INCEPTION 9 Demonstration Cases (Design by Chiara Mariotti).

Fig. 7: INCEPTION H-BIM ontology layers structure (Design by Peter Bonsma).

Fig. 8: INCEPTION, example of on-site application tested on the Italian Demonstration Case, the Istituto degli Innocenti (Design by Federico Ferrari).

Fig. 9: ROCK 3 Demonstrative areas (Design by Chiara Mariotti).

Fig. 10: Example of ROCK Atlas visualisation (https://atlas.rockproject.eu).

Fig. 11: Home page of the Innovators in Cultural Heritage Platform (www.innovatorsinculturalheritage.eu). 


\section{References \\ Baggioni, S. 2019. 5G potentials for Tourism and Education in the Cultural Heritage domain. Paper presented at the $2^{\text {nd }}$ International Conference GEORES on Cultural Heritage: challenges, new perspectives and technology innovation. Towards informative content models and beyond, Milan, Italy, May 10.}

Boeri, A., J. Gaspari, V. Gianfrate, D. Longo, and S.O.M. Boulanger. 2019. Circular city: a methodological approach for sustainable districts and communities. EcoArchitecture VII: 73-82. doi: 10.2495/ARC180071.

Boeri, A., J. Gaspari, V. Gianfrate, D. Longo. 2017. Tecnologie per l'adattamento e strategie di coprogettazione per rifunzionalizzare gli spazi storici. Techne 14: 252-259. doi: 10.13128/Techne-20800.

Chavan, S.R. 2016. Augmented Reality vs. Virtual Reality: Differences and Similarities. International Journal of Advanced Research in Computer Engineering \& Technology (IJARCET) Volume 5, Issue 6: 1947-1952. Accessed, May 22, 2019. https://pdfs.semanticscholar.org/7dda/32ae482e926941c872990840d654f9e761ba.pdf

Collins, C. 2018. Digital innovation can enhance cultural heritage, hears conference. Horizon. The EU Research \& Innovation Magazine. March 21. Accessed May 14, 2019. https://horizon-magazine.eu/article/digital-innovation-can-enhance-cultural-heritagehears-conference.html 
Comité des sages. 2011. Digital Agenda: "Comité des Sages" calls for a "New Renaissance" by bringing Europe's cultural heritage online. Brussels, January 10. Accessed May 13, 2019. http://europa.eu/rapid/press-release IP-11-17 en.htm Council of the European Union. 2014. Conclusions on cultural heritage as a strategic resource for a sustainable Europe. Education, Youth, Culture and Sport. Council meeting Brussels, Belgium, May 20. Accessed May 19, 2019. https://www.consilium.europa.eu/uedocs/cms data/docs/pressdata/en/educ/142705.pdf Council of Europe. 2005. Council of Europe Framework Convention on the Value of Cultural Heritage for Society. Faro, October 10. Accessed May 21, 2019. https://rm.coe.int/1680083746

Declaration: Cooperation on advancing of cultural heritage. Digital Day 2019, Brussels, Belgium, April 9, 2019. Accessed May 12, 2019. http://www.digiczech.eu/cms/wpcontent/uploads/2019/04/Declarationondigitisingculturalheritage.pdf

Di Giulio, R., F. Maietti, E. Piaia, M. Medici, F. Ferrari, and B. Turillazzi. 2017. Integrated data capturing requirements for $3 \mathrm{~d}$ semantic modelling of Cultural Heritage: the INCEPTION protocol. The International Archives of the Photogrammetry, Remote Sensing and Spatial Information Sciences. XLII-2/W3: 251-257. doi: 10.5194/isprsarchives-XLII-2-W3-251-2017. Accessed May 21, 2019. https://iris.unife.it/retrieve/handle/11392/2369303/88050/isprs-archives-XLII-2-W3251-2017.pdf 
Di Giulio, R., F. Maietti, and E. Piaia. 2016. 3D documentation and semantic aware representation of cultural heritage: the INCEPTION project. In Eurographics Workshop on Graphics and Cultural Heritage, ed. C.E. Catalano, and L. De Luca, L., 195-198. Goslar, Germany: The Eurographics Association. doi: 10.2312/gch.20161406.

European Commission. 2019. EU Member States sign up to cooperate on digitising cultural heritage. Brussels, Belgium, April 9. Accessed May 12, 2019. $\underline{\text { https://ec.europa.eu/digital-single-market/en/news/eu-member-states-sign-cooperate- }}$ digitising-cultural-heritage

European Commission. 2018a. Report from the Commission to the European Parliament and the Council on the evaluation of Europeana and the way forward. Brussels, September 6. Accessed May 12, 2019. https://eur-lex.europa.eu/legal$\underline{\text { content/EN/TXT/PDF/?uri=CELEX:52018DC0612\&from=EN }}$

European Commission. 2018b. Communication from the Commission to the European Parliament, the European Council, the Council, the European economic and social Committee and the Committee of the Regions. A New European Agenda for Culture. Brussels, Belgium, May 22. Accessed May 14, 2019. https://eur-lex.europa.eu/legal$\underline{\text { content/EN/TXT/PDF/?uri=CELEX:52018DC0267\&from=EN }}$

European Commission. 2018c. Commission Staff Working Document. European Framework for Action on Cultural Heritage. Brussels, Belgium, December 5. Accessed May 14, 2019. https://ec.europa.eu/culture/sites/culture/files/library/documents/staffworking-document-european-agenda-culture-2018.pdf 
European Commission. 2015. Getting cultural heritage to work for Europe. Report on the Horizon 2020 Expert Group on Cultural Heritage. Printed by Publications Office of the European Union. ISBN 978-92-79-46046-3. doi: 10.2777/745666. Accessed May 18, 2019. https://www.kowi.de/Portaldata/2/Resources/horizon2020/coop/H2020$\underline{\text { Report-Expert-Group-Cultural-Heritage.pdf }}$

European Commission. 2014. Conclusions of the Council and of the Representatives of the Governments of the Member States, meeting within the Council, on a Work Plan for Culture (2015-2018). Official Journal of the European Union, C463, 57: 4-14. Accessed May 13, 2019. https://eur-lex.europa.eu/legalcontent/EN/TXT/PDF/?uri=OJ:C:2014:463:FULL\&from=EN

European Commission. 2012. Commission Recommendation on access to and preservation of scientific information. Brussels, Belgium, July 17, 2017. Accessed May 22, 2019. http://ec.europa.eu/research/sciencesociety/document_library/pdf_06/recommendation-access-and-preservation-scientificinformation_en.pdf

European Commission. 2011. Commission Recommendation on the digitisation and online accessibility of cultural material and digital preservation. Brussels, Belgium, 
October 27. Accessed May 13, 2019. https://eur-

lex.europa.eu/LexUriServ/LexUriServ.do?uri=OJ:L:2011:283:0039:0045:EN:PDF

European Commission. 2010. Communication from the Commission to the European

Parliament, the Council, the European Economic and Social Committee and the

Committee of the Regions. A Digital Agenda for Europe. Brussels, Belgium, July 26.

Accessed May 13, 2019. https://eur-lex.europa.eu/legal-

content/EN/TXT/PDF/?uri=CELEX:52010DC0245R(01)\&from=EN

Gaspari J., S.O.M. Boulanger, and E. Antonini. 2017. Multi-layered design strategies to adopt smart districts as urban regeneration enablers, International Journal of Sustainable Development and Planning 12/8:1247-1259. doi: 10.2495/SDP-V12-N8-1247-1259.

GETTY Thesaurus. Accessed, May 23, 2019.

https://www.getty.edu/research/tools/vocabularies/aat/

INCEPTION Official Website. Accessed May 19, 2019. https://www.inceptionproject.eu

Jokilehto, J. 2005. Definition of Cultural Heritage. References to documents in history. ICCROM Working Group “Heritage and Society”. Accessed May 20, 2019.

http://cif.icomos.org/pdf docs/Documents $\% 20$ on $\% 20$ line/Heritage $\% 20$ definitions.pdf

Leeuwarden Declaration: "Adaptive re-use of the built heritage: preserving and enhancing the values of our built heritage for future generations". Leeuwarden, 
Netherlands, November 23, 2018. Accessed May 14, 2019. https://www.acecae.eu/uploads/tx jidocumentsview/LEEUWARDEN STATEMENT FINAL ENNEW.pdf

Logothetis, S., A. Delinasiou, E. Stylianidis. 2015. Building information modelling for cultural heritage: a review. The international Archives of the Photogrammetry, Remote Sensing and Spatial Information Sciences. II-5/W3: 177-183. doi: 10.5194/isprsannalsII-5-W3-177-2015. Accessed May 21, 2019. https://www.isprs-ann-photogramm$\underline{\text { remote-sens-spatial-inf-sci.net/II-5-W3/177/2015/isprsannals-II-5-W3-177-2015.pdf }}$

Maietti, F., R. Di Giulio, E. Piaia, M. Medici, F. Ferrari. 2018ạ. Enhancing Heritage fruition through 3D semantic modelling and digital tools: the INCEPTION project. In IOP Conference Series: Materials Science and Engineering 364: 1-8. Florence, Italy: IOP Publishing. doi: 10.1088/1757-899X/364/1/012089.

Maietti, F., E. Piaia, G. Mincolelli, R. Di Giulio, S. Imbesi, M. Marchi, G.A.

Giacobone, S. Brunoro. 2018ㅁ․ Accessing and Understanding Cultural Heritage

Through Users Experience Within the INCEPTION Project. In Digital Heritage. Progress in Cultural Heritage: Documentation, Preservation, and Protection, ed. R. Ioannides, E. Fink, R. Brumana, P. Patias, A. Doulamis, J. Martins, and M.s Wallace, 356-365. Cham, Switzerland: Springer. doi: 10.1007/978-3-030-01762-0_30.

Maietti, F., R. Di Giulio, M. Balzani, E. Piaia, M. Medici, F. Ferrari. 2017. Digital Memory and Integrated Data Capturing: Innovations for an Inclusive Cultural Heritage in Europe Through 3D Semantic Modelling. In Mixed Reality and Gamification for 
Cultural Heritage, ed. M. Ioannides, N. Magnenat-Thalmann and G. Papagiannakis, 225-244. Cham, Switzerland: Springer. doi: 10.1007/978-3-319-49607-8_8.

Maietti, F., F. Ferrari, M. Medici, M. Balzani. 2016ạ. 3D integrated laser scanner survey and modelling for accessing and understanding European cultural assets. In Proceedings of the International Conference SBE Malta 2016. Europe and the Mediterranean: Towards a Sustainable Built Environment, ed. R.P., Borg, P. Gauci, C.S. Staines, 317-324. Malta: Gutenberg Press.

Maietti, F., E. Piaia, and S. Brunoro. 2016. Diagnostic Integrated Procedures aimed at Monitoring, Enhancement and Conservation of Cultural Heritage Sites. In Proceedings of the International Conference SBE Malta 2016. Europe and the Mediterranean: Towards a Sustainable Built Environment, ed. R.P. Borg, P. Gauci, C.S. Staines, 309316. Malta: Gutenberg Press.

Maietti, F., E. Piaia, and B. Turillazzi. 2016. Digital Documentation: Sustainable Strategies for Cultural Heritage Assessment and Inspection. . In Proceedings of the International Conference SBE Malta 2016. Europe and the Mediterranean: Towards a Sustainable Built Environment, ed. R.P., Borg, P. Gauci, C.S. Staines, 303-308. Malta: Gutenberg Press.

Oomen, J. and R. Bočytè. 2019. Europeana Innovation Agenda. Research and innovation priorities for the European cultural heritage sector. Europeana Foundation. Accessed May 13, 2019. 
https://pro.europeana.eu/files/Europeana_Professional/Innovation_Agenda/Europeana\% 20Innovation\%20Agenda.pdf

REACH. 2019. Manifesto: "Horizon for Heritage Research". Signed at the Symposium "Horizons for Heritage Research. Towards a Cluster on Cultural Heritage", Brussels, Belgium, March 20. Accessed May 14, 2019. https://www.reach-culture.eu/wpcontent/uploads/2019/03/Manifesto-Horizon-for-Heritage-Research-draft.pdf

ROCK Official Website. Accessed May 19, 2019. https://rockproject.eu

Sonkoly, G. and T. Vahtikari. 2018. Innovation in Cultural Heritage Research. For an integrated European Research Policy. Directorate-General for Research and Innovation Europe in a changing world - Inclusive, innovative and reflective societies (Horizon 2020/SC6) and Cooperation Work Programme: Socio-Economic Sciences and Humanities (FP7. Printed by Publications Office in Luxembourg. ISBN 978-92-7978019-6. doi: 10.2777/673069. Accessed May 13, 2019. https://publications.europa.eu/en/publication-detail/-/publication/1dd62bd1-2216-11e8$\underline{\text { ac73-01aa75ed71a1 }}$

Tsakou, G. and S. Athens. 2018. Common challenges and perspectives for Digital Cultural Heritage in $\mathrm{H} 2020$ projects Building on lessons learnt and strengthening the societal impact. Report on the Workshop in Brussels, Belgium, November 14. Accessed May 14, 2019. https://ec.europa.eu/digital-single-market/en/news/common-challengesand-perspectives-digital-cultural-heritage-h2020-projects 
UNESCO Thesaurus. Accessed May 23, 2019.

http://vocabularies.unesco.org/browser/thesaurus/en/

UNESCO. 2011. Recommendation on the Historic Urban Landscape. Paris, November 10. Accessed May 20, 2016.

https://whc.unesco.org/uploads/activities/documents/activity-638-98.pdf

United Nations. 2015. Transforming our world: the 2030 Agenda for Sustainable Development. Accessed May 13, 2019.

https://sustainabledevelopment.un.org/post2015/transformingourworld

Vahtikari, T. 2018. Innovation \& Cultural Heritage. Conference Report. Royal Museum of Arts and History, Brussels, Belgium, March 20. Printed by Publications Office in Luxembourg. ISBN 978-92-79-81847-9. doi: 10.2777/303242. Accessed May 14, 2019. https://publications.europa.eu/en/publication-detail/-/publication/b1a053fd-4ceb-11e8be1d-01aa75ed71a1/language-en/format-PDF/source-70689249

Vahtikari, T. 2019. Report on the Symposium "Horizons for Heritage Research. Towards a Cluster on Cultural Heritage". Symposium results, Covent Garden, Brussels, March 20. Accessed May 12, 2019. https://www.reach-culture.eu/wpcontent/uploads/2019/05/Horizons-for-Heritage-Research-Towards-a-Cluster-onCultural-Heritage-Symposium-Report.pdf 